\section{Facilitated Advancement of the Palmaz-Schatz Stent Delivery System With the Use of an Adjacent 0.018" Stiff Wire}

\author{
Jorge F. Saucedo, MD, \\ David W.M. Muller, MBBS, FSCAl, and \\ Mauro Moscucci, MD
}

The 5.0 French Palmaz-Schatz stent delivery system is a relatively bulky, stiff system which can be advanced only over a $0.014^{\prime \prime}$ wire. Although crossing failure is rare, advancement of the delivery system through tortuous, rigid vessels may be unsuccessful. We report on four consecutive cases in which the initial advancement of the Palmaz-Schatz stent delivery system was unsuccessful due to vessel tortuosity or vessel angulation. The use of a 0.018 " stiff wirer adjacent to the Palmaz-Schatz delivery system, to "straighten" the vessels and to give additional guide catheter support, allowed for the successful advancement and delivery of coronary stents in all four cases. (c) 1996 Wiley-Llss, Inc.

Key words: percutaneous transluminal coronary angloplasty, stents, guide wire, Palmaz-Schatz stent

\section{INTRODUCTION}

By providing endoluminal mechanical support, coronary stents can seal dissection flaps and reverse abrupt closure. In addition, they provide a larger lumen when compared to conventional PTCA, which results in a lower restenosis rate [1-4]. The initial experience with the bare Palmaz-Schatz (PS) coronary stent was characterized by a significant incidence of stent embolization [5]. The addition of a covering sleeve in the new delivery system has resulted in a marked decrease of stent embolization [4], which is now rare. Although crossing failure is also rare, the 5.0 French PS stent delivery system (SDS) is a relatively bulky, rigid system which can be advanced only over a $0.014^{\prime \prime}$ wire [6]. Thus, its advancement through tortuous or angulated vessels may be unsuccessful $[4,7-9]$.

We report our experience of four consecutive cases in

From the Division of Cardiology, Department of Internal Medicine, University of Michigan Medical Center, Ann Arbor, Michigan.

Received January 22, 1996; revision accepted April 16, 1996.

Address reprint requests to Mauro Moscucci, M.D., University of Michigan Medical Center, 1500 East Medical Center Drive, B1F245 University Hospital, Ann Arbor, MI 48109-0022. which the initial advancement of the Palmaz-Schatz stent delivery system was unsuccessful due to vessel tortuosity or vessel angulation. The use of an adjacent $0.018^{\prime \prime}$ stiff wire, to "straighten" the vessel and to provide additional guide catheter support, allowed the advancement and optimal deployment of the PS coronary stent.

\section{CASE 1}

A 58-yr-old man, status postcoronary artery bypass surgery (CABG) in 1990 with a left internal mammary artery (LIMA) graft and three saphenous vein grafts (SVG), was admitted with a 1-yr history of stable angina. A stress thallium test showed a large, reversible lateral defect. Selective coronary angiography showed that the proximal left anterior descending coronary artery (LAD) was totally occluded. The left circumflex (LCX) had a complex, eccentric $90 \%$ stenosis in the proximal third, and a complex, ulcerated, long $90 \%$ stenosis in midthird (Fig. 1A). The right coronary artery (RCA) was diffusely diseased and had a 70\% stenosis in its distal third before its bifurcation. The SVGs to the obtuse marginal (OM) and to the RCA were both occluded. An SVG to the native LAD was patent, but the LIMA to the LAD was occluded in its distal third. A PTCA of both LCX lesions was planned. Using an 8F JL4 guiding catheter, the stenoses were crossed with a $0.014^{\prime \prime} \mathrm{Hi}$-Torque Extra S'port wire (ACS, Santa Clara, CA). Attempts to advance a 3.0-mm Panther balloon (Medtronic, San Diego, CA) across the proximal stenosis were unsuccessful due to the presence of a sharp angle at the origin of the LCX and to the severity of the stenosis immediately after this angle (Fig. 1A). A 3.0-mm Ace balloon (Sci-Med, Maple Grove, MN) was then successfully advanced across the two stenoses alongside the $0.014^{\prime \prime}$ Hi-Torque floppy wire [10]. Multiple inflations were performed at the site of the proximal and midstenoses to a maximum of $8 \mathrm{~atm}$. Repeat angiography revealed a $40 \%$ residual stenosis with haziness in the proximal lesion. Additional inflations to a maximum of $10 \mathrm{~atm}$ were performed with the $3.0-\mathrm{mm}$ Panther balloon, which was this time advanced successfully through the stenosis. Repeat angiography still revealed suboptimal results. Attempts to advance a PS stent delivery system (Johnson and Johnson, Interventional Systems Co., Warren, NJ) through the origin of the LCX were unsuccessful due to the proximal angulation. The $0.014^{\prime \prime} \mathrm{Hi}$-Torque Extra S'port wire was exchanged for a 0.014" Platinum plus stiff wire (Medi-Tech, Natick, MA). Despite the added stiffness in the guide wire system, additional attempts to advance the stent were unsuccessful. A $0.018^{\prime \prime}$ Platinum 
plus ST wire (Medi-Tech) was advanced alongside the $0.014^{\prime \prime}$ wire (Fig. 1B). The second stiff guide wire was successful in straightening the proximal portion of the artery. The stent delivery system was successfully advanced across the proximal stenosis. The $0.018^{\prime \prime}$ wire was withdrawn and the stent was then successfully deployed. After its deployment, a dissection was noted in the midlesion. Therefore, two additional PS coronary stents were deployed at this site. The three stents were postdilated in sequence with a $3.0-\mathrm{mm}$ and a $3.5-\mathrm{mm} \mathrm{NC}$ Cobra balloon (Sci-Med) at $18 \mathrm{~atm}$. The final angiography revealed a negative residual stenosis with TIMI 3 flow (Fig. 1C). The patient was discharged the day after the procedure on ticlopidine ( $250 \mathrm{bid}$ ), and he was symptom free at 4 mo of follow-up.

\section{CASE 2}

A 64-yr-old man, with a past medical history of single-vessel CABG in 1982 (SVG to the LAD), presented with unstable angina and ischemic EKG changes in the anterior leads. Cardiac catheterization revealed severe three-vessel coronary artery disease and occlusion of the LAD graft. CABG was initially attempted but aborted after a thoracotomy revealed heavy calcification of the aorta. He continued to have unstable angina despite maximal medical treatment, and he was therefore referred to our institution for percutaneous coronary revascularization. Left ventriculography showed preserved left ventricular systolic performance with a left ventricular ejection fraction of $60 \%$. Coronary angiography showed heavy calcification of the coronary arteries. The left main coronary artery (LMCA) had mild irregularities. The LAD had an $80 \%$ stenosis in its origin and a $90 \%$ angulated stenosis in its mid third. The LCX was totally occluded (Fig. 2A,B). The RCA had a $60 \%$ proximal and a $70 \%$ distal stenosis and supplied collaterals to the LCX. Rotational atherectomy followed by coronary stenting of the LAD, with intraaortic balloon pump support, was planned. The lesions were crossed with a type $\mathrm{C}$ rotablator wire (Heart Technology, Redmond, WA). One pass with polishing runs was performed with a 1.25-mm Rotablator burr (Heart Technology) through the proximal and midstenoses, and with a $1.75-\mathrm{mm}$ Rotablator burr only through the proximal lesion. Both lesions were postdilated with a $2.5-\mathrm{mm}$ Panther balloon (Medtronic) in preparation for the deployment of two PS stents. The type $\mathrm{C}$ rotablator wire was exchanged for a 0.014" Extra S'port wire (ACS) through the Panther balloon. The balloon was then exchanged for a $3.0-\mathrm{mm}$ PS coronary stent delivery system (Johnson and Johnson). Attempts to advance the coronary stent to the mid-LAD lesion were unsuccessful due to vessel tortuosity and calcification. The stent delivery system was therefore
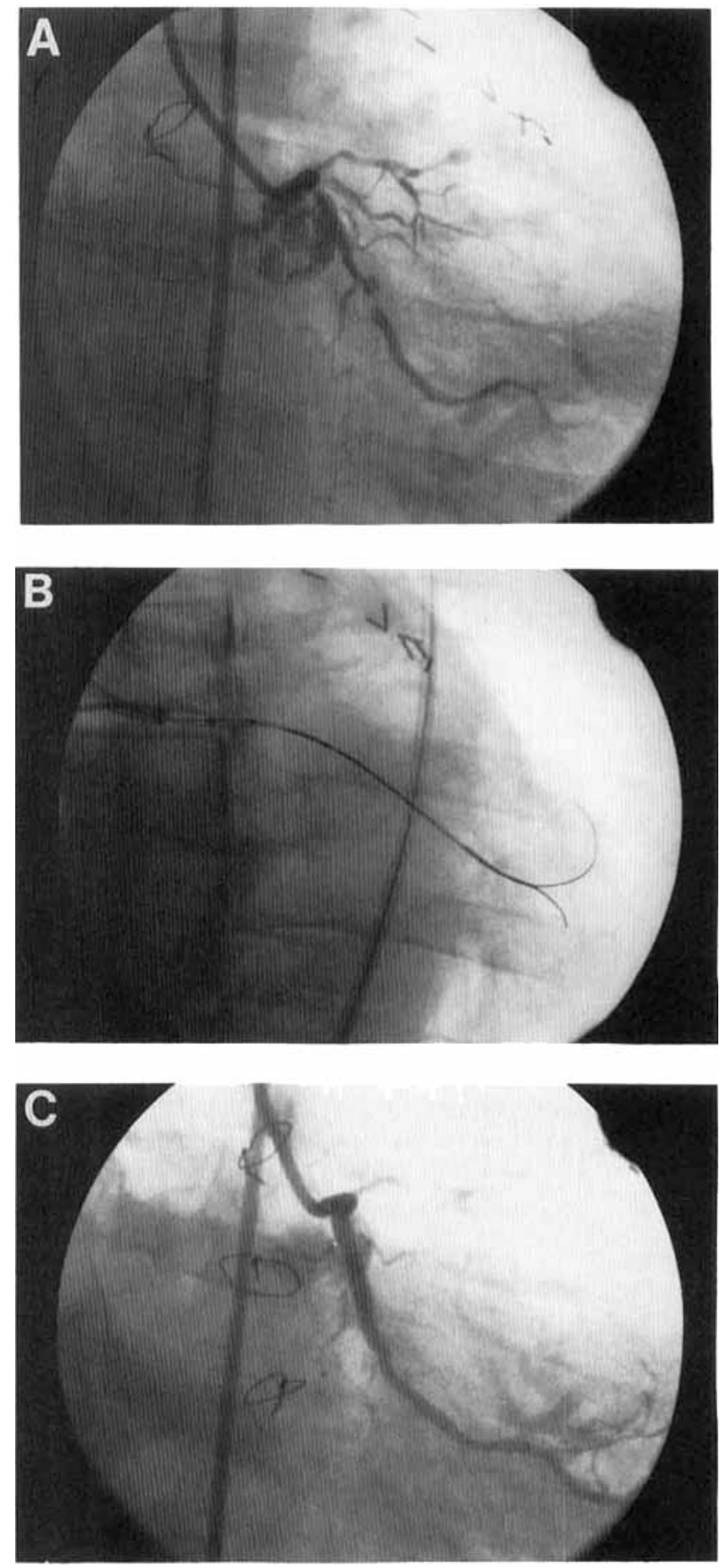

Fig. 1. A: Pre-PTCA coronary angiogram in RAO view. There is a mid-LAD occlusion and severe proximal and midleft circumflex stenoses with a significant proximal angulation. B: Advancement of the stent delivery system over a 0.014" Platinum plus guide wire with an adjacent $0.018^{\prime \prime}$ Platinum plus wire. C: After deployment of three coronary stents, repeat angiography shows no residual stenosis.

removed, and an $18 \mathrm{~K}$ balloon (Medtronic, Moundsview, MN) was advanced to the distal LAD over the $0.014^{\prime \prime}$ wire. The $0.014^{\prime \prime}$ wire was exchanged through the 

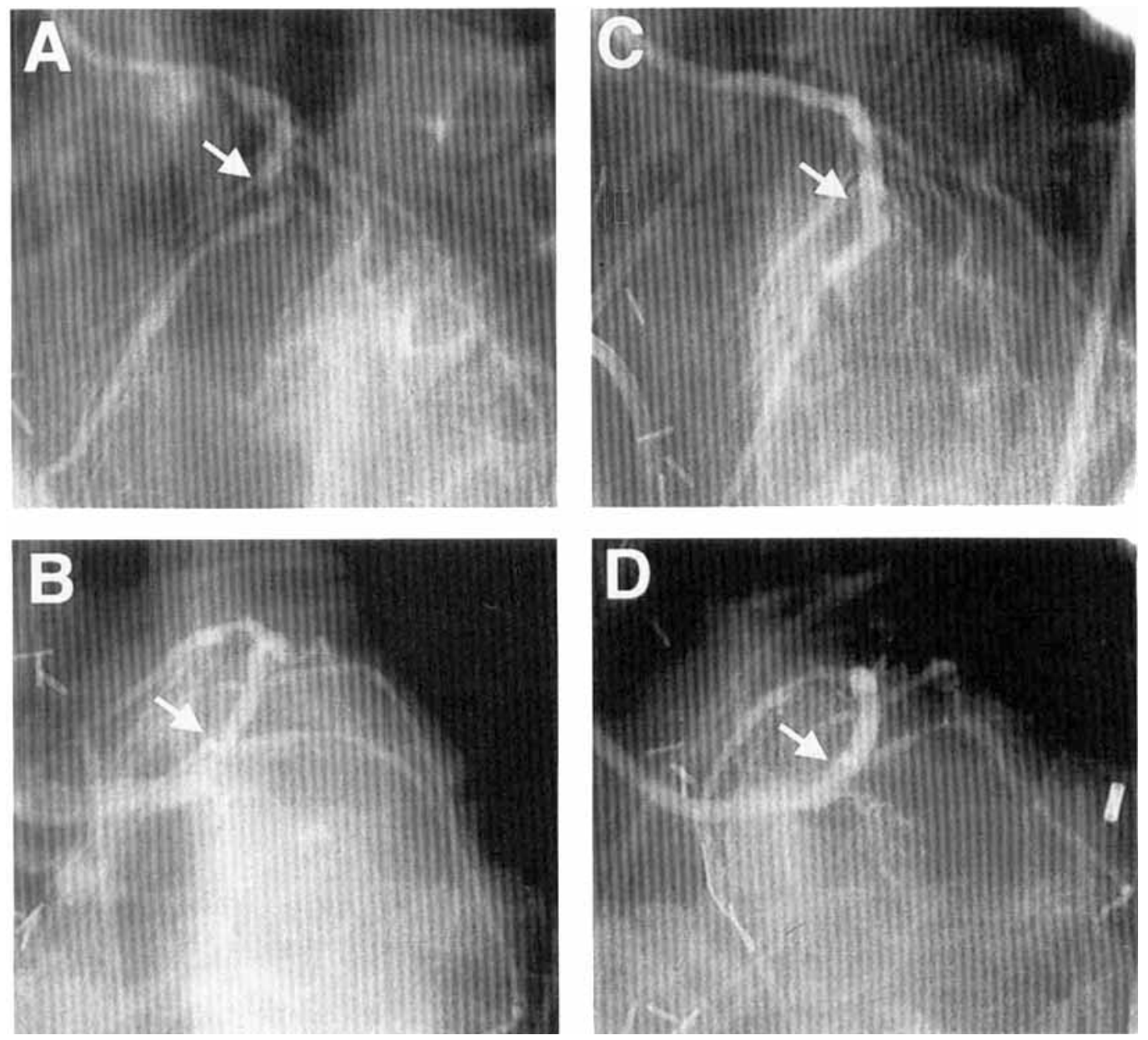

Fig. 2. Cineangiograms in LAO cranial view (A) and LAO caudal view (B) show an $80 \%$ stenosis at the origin of the LAD (arrow) and a $90 \%$ stenosis in the mid-LAD (arrow). Repeat cin-

$18 \mathrm{~K}$ balloon for a $0.018^{\prime \prime}$ Platinum Plus ST stiff guide wire (Medi-Tech). The $18 \mathrm{~K}$ balloon was removed, and a second 0.014" Hi-Torque Extra S'port wire (ACS) was advanced through the proximal and midlesions alongside the $0.018^{\prime \prime}$ wire. The PS coronary stent was then advanced without difficulties over the $0.014^{\prime \prime}$ wire through the midlesion. The $0.018^{\prime \prime}$ wire was withdrawn, and the PS coronary stent was successfully deployed in the midlesion. A second PS coronary stent was successfully deployed in the proximal LAD lesion. With intravascular ultrasound guidance, both stents were postdilated in sequence with a $3.0-\mathrm{mm}$ and a $3.5-\mathrm{mm}$ NC Cobra balloon (Sci-Med), to a maximum of $16 \mathrm{~atm}$ (Fig. 2C,D). The patient was discharged on the second postprocedure day in stable condition on oral warfarin (INR $>2$ ) and aspirin (325 mg QD). At 3 mo of follow-up, he remains free of cardiac symptoms.

eanglograms in LAO cranial view (C) and LAO caudal view (D) obtained after stent deployment show excellent results at both sites (arrows).

\section{CASE 3}

A 59-yr-old man presented with an inferior myocardial infarction complicated by postinfarction angina. Coronary angiography $2 \mathrm{wk}$ after the MI showed a $90 \%$ concentric distal RCA stenosis (Fig. 3A). A 0.014" HiTorque Extra S'port wire was used to cross the stenosis, and a 4.0-mm Lifestream balloon (ACS) was used to dilate the lesion. After multiple prolonged inflations, the result was suboptimal and it was decided to proceed with coronary stenting. Attempts to advance a $4.0-\mathrm{mm}$ PS coronary stent were surprisingly unsuccessful, possibly due to proximal angulation of the RCA and inadequate guiding catheter support. A 0.018" Platinum Plus ST stiff wire (Medi-Tech) was advanced to the distal RCA to straighten the vessel. A PS stent was then successfully advanced over the $0.014^{\prime \prime}$ wire (Fig. 3B). The stent was 
postdilated with a $4.0-\mathrm{mm}$ Lifestream balloon (ACS). Repeat coronary angiography performed after balloon postdilatation revealed inadequate stent expansion. Attempts to advance a $5.0-\mathrm{mm}$ Total Cross balloon (Schneider, Minneapolis, MN) through the proximal RCA were unsuccessful. The $0.018^{\prime \prime}$ Platinum Plus wire was readvanced to the distal RCA, and the Total Cross balloon was then successfully advanced through the stent. Final angiography revealed a negative residual stenosis (Fig. 3C). The patient was discharged home the day after the procedure on aspirin ( $325 \mathrm{mg}$ QD) and ticlopidine ( $250 \mathrm{mg}$ bid). At 3 mo of follow-up, he was free of cardiovascular symptoms.

\section{CASE 4}

An 82-yr-old man status post-CABG presented with unstable angina, 6 mo after having had PTCA and rotational atherectomy of a calcified ostial LAD and RCA. Repeat cardiac catheterization showed an $80 \%$ proximal LAD stenosis. Rotational atherectomy and stenting of the proximal LAD were planned. After rotational atherectomy was performed, multiple attempts to advance a PS coronary stent delivery system failed. A $0.018^{\prime \prime}$ Platinum Plus ST stiff wire (Medi-Tech) was used to overcome the lack of support from the left Judkins guiding catheter. The stent delivery system was then successfully advanced over a 0.014" Hi-Torque Extra S'port wire, allowing stent deployment after the $0.018^{\prime \prime}$ wire was withdrawn. TIMI 3 flow with a negative residual stenosis was obtained. At 6 mo of follow, the patient had stable NYHA class 2 symptoms and no angina.

\section{DISCUSSION}

Stent deployment in tortuous, calcified coronary arteries may be limited by inadequate stent expansion or unsuccessful stent delivery [7]. The current generation of PS coronary stents is mounted on a balloon that does not accommodate a stiff $0.018^{\prime \prime}$ wire. The $1-\mathrm{mm}$ central articulation facilitates the advancement of the delivery system through the proximal vessel to distal lesions. However, vessel angulation and rigidity may result in unsuccessful stent delivery [11]. In addition, although the delivery system may be advanced over a stiff $0.014^{\prime \prime}$ wire, this may be inadequate to overcome vessel tortuosity or angulation. We describe here the successful deployment of PS coronary stents in cases in which initially the advancement of the stent delivery system was not possible. In each case, the use of an additional $0.018^{\prime \prime}$ stiff wire alongside the PS delivery system allowed successful stent deployment over a $0.014^{\prime \prime}$ wire.

In cases 2 and 4 , the $0.018^{\prime \prime}$ wire was placed in the distal vessel using a $0.018^{\prime \prime}$ compatible balloon previ-
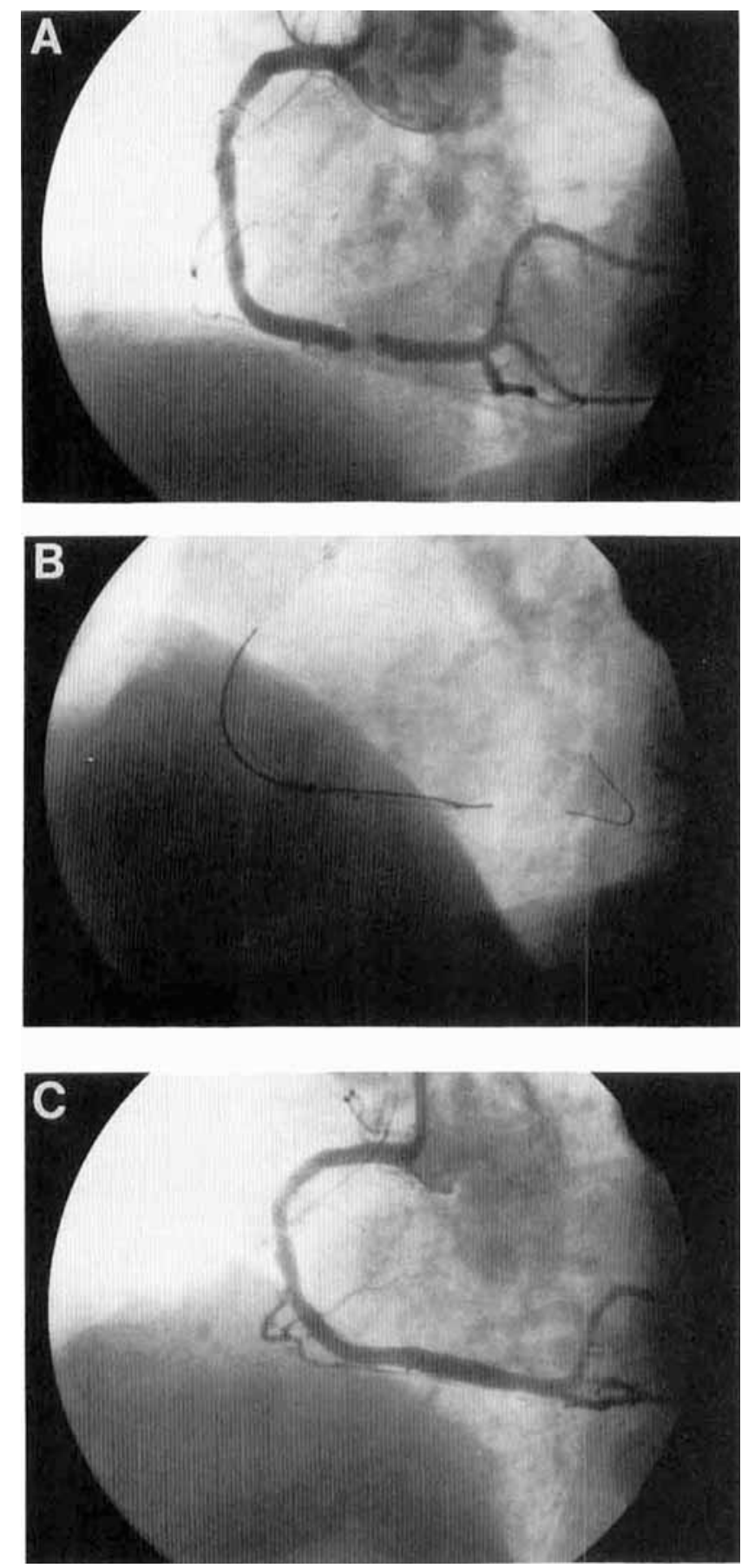

Fig. 3. A: Cineangiogram in LAO view shows a $90 \%$ stenosis in the distal third of the RCA. B: Advancement of the stent delivery system over a 0.014" Extra S'port wire with an adjacent $0.018^{\prime \prime}$ Platinum plus wire. C: Final angiogram after postdilatation with the 5.0-mm Total Cross balloon shows a $-20 \%$ stenosis.

ously advanced over a more flexible $0.014^{\prime \prime}$ wire. In none of these cases was there a complication related to the procedure. In case 1, a distal dissection was noted after the proximal LCX had been stented. We attributed 
this dissection to the advancement of the $0.018^{\prime \prime}$ platinum wire through the previously dilated artery without the protection of a balloon catheter. Therefore, it appears advisable to advance the $0.018^{\prime \prime}$ stiff wire through a balloon catheter, and to recross the lesion with a softer 0.014 " wire. Care is also needed in removing the platinum wire before expanding the stent, as failure to do so could trap the wire between the deployed stent and the vessel wall.

In case 3, the Palmaz-Schatz delivery system could not be advanced through the proximal RCA despite the use of a $0.014^{\prime \prime}$ extra support wire, and despite adequate retraction of the sheath over the stent balloon system. Failure to advance the stent delivery system was presumably due to the sharp angle at the junction between the proximal and mid third of the vessel, and to inadequate guiding catheter support. Interestingly, the high-profile, stiff Total Cross balloon could also not be advanced through the proximal third of the vessel without the adjunctive use of the $0.018^{\prime \prime}$ extra-stiff wire. As shown in Figure 3 , the use of the extra-stiff 0.018 " wire resulted in straightening of the vessel, and provided additional guiding catheter support.

In case 4 , the stiff wire offered the needed support to advance and deploy the stent in the proximal LAD. In this patient, the stiff wire appeared to anchor the guide catheter and to provide substantially greater catheter backup. Failure to obtain additional backup would have made it necessary to change the guide catheter. Of note, in none of these cases was an Amplatz guide catheter used. Whether the additional support provided by an Amplatz catheter would have resulted in successful stent deployment without the need for the $0.018^{\prime \prime}$ stiff wire is unknown. In addition, we cannot rule out that the procedures would have been successful with one of the newer stent designs and stent delivery systems which, however, are not yet available on the US market.

In conclusion, as the use of coronary stents is rapidly growing, difficulties in their deployment will be encountered. The use of an additional $0.018^{\prime \prime}$ stiff wire alongside the stent delivery system allows straightening of tortuous or angled vessels and provides additional backup for successful stent deployment.

\section{REFERENCES}

1. Serruys PW, de Jaegere P, Kiemeneij F, Macaya C, Rutsch W, Heyndrickx G, Emanuelsson H, Marco J, Legrand V, Materne P,
Belardi J, Sigwart U, Colombo A, Goy JJ, Van Den Heuvel P, Delcan J, Morel MA: A comparison of balloon-expandable-stent implantation with balloon angioplasty in patients with coronary artery disease: BENESTENT Study Group. N Engl J Med 331: 489-495, 1994.

2. Fischman DL, Leon MB, Baim DS, Schatz RA, Savage MP, Penn I, Detre K, Veltri L, Ricci D, Nobuyoshi M, Cleman M, Heuser R, Almond D, Teirstein PS, Fish D, Colombo A, Brinker J, Moses J, Shaknovich A, Hirshfeld J, Bailey S, Ellis S, Rake R, Goldberg S: A randomized comparison of coronary-stent placement and balloon angioplasty in the treatment of coronary artery disease: Stent Restenosis Study Investigators. N Engl J Med 331: 496-501, 1994.

3. Savage MP, Fischman DL, Schatz RA, Teirstein PS, Leon MB, Baim D, Ellis SG, Topol EJ, Hirshfield JW, Cleman MW, Buchbinder M, Bailey S, Heuser R, Walker CM, Curry RC, Gebhardt $S$, Rake $R$, Goldberg S: Long-term angiographic and clinical outcome after implantation of a balloon-expanded stent in the native coronary circulation. J Am Coll Cardiol 24:1207-1212, 1994

4. Carrozza JP, Kuntz RE, Levine MJ, Pomerantz RM, Fishman RF, Mansour M, Gibson CM, Senerchia CC, Diver DJ, Safian RD, Baim DS: Angiographic and clinical outcome of intracoronary stenting: Immediate and long-term results from a large single-center experience. J Am Coll Cardiol 20:328-337, 1992.

5. Schatz RA, Baim DS, Leon M, Ellis SG, Goldberg S, Hirshfeld JW, Cleman MW, Cabin HS, Walker C, Stagg J, Buchbinder M, Teirstein PS, Topol EJ, Savage M, Perez JA, Curry RC, Whitworth H, Sousa E, Tio F, Almagor Y, Ponder R, Penn IM, Leonard B, Levine SL, Fish RD, Palmaz JC: Clinical experience with the Palmaz-Schatz coronary stent. Circulation 83:148-161, 1991.

6. Kelley LR, Teirstein P, Schatz RA: Slotted-tube metallic stents. In Ellis SE, Holmes DR Jr (eds): “Strategic Approaches to Coronary Interventions." Baltimore: Williams \& Wilkins, 1996, pp 85-96.

7. Satler LF: The frustration of coronary stenting. Cathet Cardiovasc Diagn 35:216-217, 1995.

8. Hirshfeld JW, Herrmann HC: Stent deployment; technical considerations. In Herrmann HC, Hirshfeld JW (eds): "Clinical Use of the Palmaz-Schatz Intracoronary Stent." Mount Kisco, NY: Futura Publishing, 1993, pp 23-42.

9. Wong SC, Popma JJ, Pichard AD, Kent KM, Satler LF, Mintz GS, Chuang YC, Hong MK, Ditrano CJ, Leon MB: Comparison of clinical and angiographic outcomes after saphenous vein graft angioplasty using coronary versus biliary tubular slotted stents. Circulation 91:339-350, 1995.

10. Selig MB: Lesion protection during fixed-wire balloon angioplasty: Use of the "Buddy Wire" technique and access catheters. Cathet Cardiovasc Diagn 25:331-335, 1992.

11. Wong SC, Schatz RA: Developmental background and design of the Palmaz-Schatz coronary stents. In Herrmann HC, Hirshfeld JW (eds): "Clinical Use of the Palmaz-Schatz Intracoronary Stent." Mount Kisco, NY: Futura Publishing, 1993, pp 3-19. 